\title{
Erratum to: Amphibious auditory evoked potentials in four North American Testudines genera spanning the aquatic-terrestrial spectrum
}

\author{
Jeffrey N. Zeyl ${ }^{1}$ Carol E. Johnston ${ }^{1}$
}

Published online: 11 May 2016

(C) Springer-Verlag Berlin Heidelberg 2016

\section{Erratum to: J Comp Physiol A (2015) 201:1011-1018 DOI 10.1007/s00359-015-1031-6}

Additional measurements of the pressure gradient using two hydrophones revealed an error in the particle acceleration reported for $10 \mathrm{~cm}$ below the surface in Table 1. At this location, particle accelerations were in fact $4.5-8.5 \mathrm{~dB}$ lower than at the surface, rather than $12-16 \mathrm{~dB}$ lower. After repeated measurements of the test chamber under identical conditions, we could not replicate the reported values at $10 \mathrm{~cm}$ below the surface, but found no errors in our calculations. Therefore, we attribute the error to a lowered recording setting on the digital recorder during acquisition. The figure and table below show 3 additional measurements taken at the surface and at $10 \mathrm{~cm}$ below the surface in relation to the originally reported values. Values represent the mean and s.e.m of the particle acceleration combined across 3 measured axes. All measurements were taken around a center point calibrated to a sound pressure level of $126 \mathrm{~dB}$ re $1 \mu \mathrm{Pa}$. The results do not change our interpretation of comparisons between species, since it indicates that the sound field experienced by Sternotherus spp. was more similar to the conditions for T. carolina carolina and T. scripta tested at the surface.

The online version of the original article can be found under doi:10.1007/s00359-015-1031-6.

Jeffrey N. Zeyl

jnz0002@tigermail.auburn.edu

Fish Biodiversity Lab, School of Fisheries, Aquaculture, and Aquatic Sciences, College of Agriculture, Auburn University, Auburn, AL 36849, USA
Table Particle acceleration in $\mathrm{dB}$ re $1 \mathrm{~m} / \mathrm{s}^{2}$ for original and additional measurements at the surface and $10 \mathrm{~cm}$ below the surface

\begin{tabular}{lllll}
\hline & $\begin{array}{l}\text { Surface } \\
\text { (original) }\end{array}$ & $\begin{array}{l}\text { Surface } \\
\text { (additional } \\
\text { measurements) }\end{array}$ & $\begin{array}{l}10 \mathrm{~cm} \text { deep } \\
\text { (original) }\end{array}$ & $\begin{array}{l}10 \mathrm{~cm} \text { deep } \\
\text { (additional } \\
\text { measurements) }\end{array}$ \\
\hline $100 \mathrm{~Hz}$ & -17.73 & -20.60 & -33.51 & -26.87 \\
$200 \mathrm{~Hz}$ & -21.22 & -19.99 & -34.38 & -28.46 \\
$300 \mathrm{~Hz}$ & -21.18 & -20.43 & -34.24 & -26.10 \\
$400 \mathrm{~Hz}$ & -19.29 & -19.57 & -32.32 & -25.12 \\
$500 \mathrm{~Hz}$ & -19.02 & -20.29 & -31.57 & -25.19 \\
$600 \mathrm{~Hz}$ & -19.41 & -16.82 & -32.47 & -25.18 \\
$700 \mathrm{~Hz}$ & -19.66 & -17.01 & -31.44 & -24.05 \\
$800 \mathrm{~Hz}$ & -18.84 & -19.26 & -31.28 & -23.79 \\
\hline
\end{tabular}

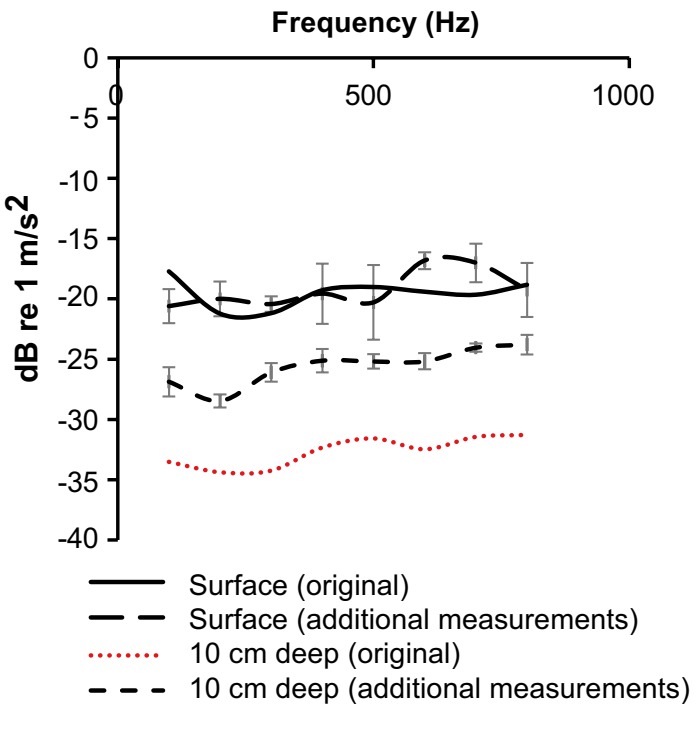

